shunt) in this group. This compares favourably with a postmortem study of normal hearts that showed the incidence of patent foramen ovale to be about $27 \%$.

We conclude that the presence of a right to left shunt in a diver without a history of decompression sickness may be irrelevant. On current information, there is probably not a case for the routine screening of divers (or, indirectly, potential divers) for shunts.

We thank Lynne Macbeth for her help in performing the echocardiographic examinations.
1 Wilmshurst PT, Byrne JC, Webb-Peploe MM. Relation between interatrial shunts and decompression sickness in divers. Lancet 1989;ii:1302-6. 2 Moon RE, Camporesi EM, Kissilo JA. Patent foramen ovale and decompression sickness in divers. Lancet 1989;i:513-4.

3 Lechat PH, Mas JL, Lascault G, Loron PH, Theard M, Klimczag M, et al. Prevalence of patent ovale in patients with stroke. $N$ Engl f Med 1988;318: 1148-52.

4 Shub C, Tajik AJ, Seward JB, Dines DE. Detecting intra-pulmonary right-toleft shunt with contrast echocardiography. Observations in a patient with diffuse pulmonary arteriovenous fistulas. Mayo Clin Proc 1976;51:81-4.

5 Hagen PT, Scholz DG, Edwards WD. Incidence and size of patent foramen ovale during the first 10 decades of life: an autopsy study of 965 normal hearts. Mayo Clin Proc 1984;59:17-20.

(Accepted 10 October 1991)

\section{Plantar power: reproducibility of the plantar response}

\author{
J Maher, M Reilly, L Daly, M Hutchinson
}

Department of Neurology, Adelaide Hospital, Dublin 8

J Maher, MRCPI, senior house officer

M Reilly, MRCPI, registrar

M Hutchinson, FRCP,

consultant neurologist

Department of Public

Health Medicine and

Epidemiology, University

College, Dublin

L Daly, PHD, senior lecturer

Correspondence to:

Dr Hutchinson.

BMF 1992;304:482 lesions. ${ }^{12}$ in its detection by 24 physicians.
Babinski's sign is an established part of neurological examinations, regarded widely as the key clinical sign of pyramidal tract disturbance. The specificity and sensitivity of the sign have never been studied as there is no standard test to indicate both the anatomical and the physiological integrity of the descending pathways. There is, none the less, much evidence linking the presence of the sign with pure corticospinal tract

To be of practical diagnostic value all clinical signs must be both valid and reproducible. In view of the inherent difficulties in documenting the validity of Babinski's sign we examined its reproducibility by assessing the intraobserver and interobserver variation

\section{Patients, methods, and results}

Twelve patients with multiple sclerosis (five), cerebral infarction (two), spondylotic myelopathy (two), Wilson's disease (one), diabetes mellitus (one), and epilepsy (one) were chosen for the study. Twenty four physicians (seven consultants and 17 experienced non-consultant hospital doctors) were divided into six groups of four. Each group member examined the same two patients (four plantar responses) on two separate occasions, making a total of 192 examinations. The extent of agreement within each group of four physicians in the first examination of two patients was assessed (interobserver variation). Intraobserver variation was based on comparison of the first and second examinations of the four plantar responses by the 24 physicians. Patients were screened so only their feet were visible, and physicians were told that they had to examine four patients (rather than two patients on two occasions as was the case). Each plantar response was graded as upgoing or downgoing; an equivocal response was not accepted.

For statistical analysis the $\chi$ statistic was calculated. This is a measure of agreement and can be interpreted as the percentage agreement beyond chance. $A x$ value of $100 \%$ implies perfect agreement between observers, a value of $0 \%$ agreement due purely to chance. A $x$ for interobserver variation was calculated in each of the six groups of four physicians using the results from the first examination. The overall $x$ was based on averaging these six estimates. For intraobserver variation a $x$ statistic was calculated for each of the 24 physicians based on the duplicate interpretations of the four plantar responses. These $24 x$ values were averaged to give an overall measure of intraobserver variation. Details are to be found in Fleiss. ${ }^{3}$ Results were expressed as $95 \%$ confidence intervals.
Interobserver variation - In only $50 \%$ of the examinations was there total agreement between the four doctors (table). The average percentage agreement beyond chance was $16 \cdot 7 \%(0 \cdot 4 \%$ to $33 \cdot 0 \%)$.

Agreement between physicians on nature of plantar responses (interobserver variations) and by each physician examining four plantar responses on two occasions (intraobserver variation)

\begin{tabular}{cc|cc}
\hline \multicolumn{2}{c|}{ Interobserver variation } & & \multicolumn{2}{c}{ Intraobserver variation } \\
\cline { 5 - 5 } $\begin{array}{c}\text { Extent of } \\
\text { agreement between } \\
\text { four physicians }\end{array}$ & $\begin{array}{c}\text { No of plantar } \\
\text { responses }\end{array}$ & $\begin{array}{c}\text { No of plantar } \\
\text { responses that } \\
\text { agreed }\end{array}$ & $\begin{array}{c}\text { No of } \\
\text { physicians } \\
\text { agreeing }\end{array}$ \\
\hline Complete & 12 & 4 & 14 \\
3/1 split & 7 & 3 & 6 \\
2/2 split & 5 & 2 & 3 \\
\hline Total & 24 & Total & 24 \\
\hline
\end{tabular}

Intraobserver variation - Fourteen physicians agreed completely with their assessments of all four plantar responses on the two separate occasions (table). The $x$ statistic averaged over the 24 physicians was $59 \cdot 6 \%$ $(39 \cdot 6 \%$ to $79 \cdot 6 \%)$.

\section{Comment}

Our data indicate that experienced physicians often disagree about the nature of the plantar response. Though intraobserver consistency was somewhat more impressive, our results clearly call into question the clinical value of this established sign. Other explanations for our findings are that $(a)$ the physicians were not experienced in eliciting the sign or $(b)$ the plantar responses in our patients were intrinsically variable. However, we deliberately chose physicians with some years of clinical experience, all of whom were members or fellows of a royal college, and the patients studied were those from a neurology ward who were deemed by us to have definite plantar responses of one or other type.

A high frequency of extensor plantar reflexes, without other pyramidal tract signs, has been reported in a population of elderly patients with psychiatric disease. ${ }^{4}$ McCance $e t$ al noted that the reproducibility of the sign was poor and cautioned against overemphasising its value in this age group. Nathan and Smith counselled that the plantar reflex should be interpreted only as part of the complete physical examination ${ }^{5}$ and our study reemphasises the difficulty in basing clinical decisions on any single physical sign.

1 Chokroverty S, Rubino FA, Haller C. Pure motor hemiplegia due to pyramida infarction. Arch Neurol 1975;32:647-8.

2 Leestma JE, Noronha A. Pure motor hemiplegia, medullary pyramid lesion and olivary hypertrophy. F Neurol Neurosurg Psychiatry 1976;39:877-84.

3 Fleiss JL. Statistical methods for rates and proportions. 2nd ed. New York: Wiley, 1981:212-36.

4 McCance C, Watt JA, Hall DT. An evaluation of the reliability and validity of the plantar response in a psychogeriatric population. $\mathcal{F}$ Chronic Dis 1968;21: 369-74.

5 Nathan PW, Smith MC. The Babinski response: a review and some new observations. I Neurol Neorosurg Psychiatry 1955;18:250-9.

(Accepted 8 October 1991) 